\title{
Adirondack Park Incidents: A Retrospective Review of Search and Rescue Reports From 2008 and 2009
}

\author{
Rokhsanna Sadeghi, MD; Joseph C. Konwinski, MD; Rita K. Cydulka, MD, MS \\ From the Department of Emergency Medicine, Metrohealth Medical Center, Cleveland, OH (Dr Sadeghi); the Emergency Services Institute, the Cleveland \\ Clinic, Cleveland, $\mathrm{OH}$ (Dr Konwinski); and the Department of Emergency Medicine, Metrohealth Medical Center, Cleveland, $\mathrm{OH}$ (Dr Cydulka).
}

Background.- - The Adirondack Park is a 6 million acre recreational area in northeastern New York used for activities such as hiking, camping, canoeing, hunting, fishing, snowmobiling, skiing, and rock climbing. Given the large number of people who use the Adirondacks for recreation, there exists the potential for many accidents, injuries, and illnesses to occur in areas ranging from state-operated campgrounds to remote backcountry.

Objective.-The aim of this study was to gain insight into the demographics of search and rescue (SAR) operations in the Adirondack Park.

Methods.- This study is a retrospective review of the Adirondack Park Forest Ranger SAR reports from January 1, 2008, through December 31, 2009. Epidemiologic data were gathered from the NY State Department of Environmental Conservation for each report, including victim demographics, incident, reason for injury, medical care needed, preparation of victim, and prior medical conditions.

Results.-In all, 239 SAR missions were carried out involving at least 349 victims. Of all cases, 28\% (66) involved an injured victim, and 9\% (21) involved illness; 56\% (10) of the victims had a known prior illness or medical condition; and $21 \%$ (27) of cases were due to victims exceeding their abilities. Of the search missions, $54 \%$ of victims (93) had little experience with the activity, and $9 \%$ (15) had no experience. Only 43\% (62) of victims had any form of orientation equipment.

Conclusions.- This study portrays the initial demographics of SAR efforts in Adirondack Park. It will aid in educating people on preparing for wilderness activities, as well as tailoring SAR resources to the demographics of injury and illness within the park.

Key words: search and rescue, wilderness injuries and illnesses, Adirondack, New York

\section{Introduction}

The Adirondack Park is a 6 million acre recreational area in northeastern New York used for activities such as hiking, camping, canoeing, hunting, fishing, trapping, snowmobiling, skiing, mountain biking, and rock climbing. ${ }^{1}$ The Adirondack Park encompasses a mixture of mountains, forest, wetlands, and waterways and is the largest park in the lower 48 United States. There are an estimated 130,000 people who live within the park year round and another 45,000 seasonal residents. It is estimated that there are more than 5 million visits to the Adirondacks for recreation every year.

Given the large number of people who use the Adirondacks for recreation year round, the potential

Corresponding author: Rokhsanna Sadeghi, MD, 200 Hook Road, Farmington, NY 14425 (e-mail: rokhsanna@gmail.com). exists for many accidents, injuries, and illnesses to occur in areas ranging from state-operated campgrounds to remote backcountry. The Adirondacks is a unique area with a terrain that varies greatly, and poses unique challenges for first responders. ${ }^{2-10}$ Forest rangers are most often the first responders for search and rescue (SAR) operations in the Adirondacks. These rangers are trained in wilderness medicine first response, search management, national incident command system, map and compass, search techniques, and the use of global positioning system (GPS) units. The rangers are often assisted by State Police, the local sheriff, the local fire department, and 911 county dispatch.

The SAR operations are emergent responses by trained personnel to aid persons who are in distress, ill, or injured, or possibly lost. ${ }^{2}$ The SAR missions are classified as to whether they involve searching for individuals only or making a rescue attempt, or both. 
The aging population has become more involved in outdoor and wilderness activities. ${ }^{11,12}$ Older persons are likely to have medical comorbidities, which poses a new challenge for first responders who are providing care to persons involved in SAR missions. The epidemiology of injuries and illnesses specific to people aged more than 65 years has never been described, nor have the details of SAR in the Adirondack Park.

The objective of this retrospective review is to gain insight into the types and patterns of injuries that occur in the Adirondack Park, as well as to obtain a better understanding of the population that experiences these accidents or injuries while in the park. In addition, a goal of this study is to better elucidate the cause of these incidents to guide preparedness of persons entering the wilderness areas and help prevent injuries and illness.

\section{Methods}

This study is a retrospective review of the Adirondack Park Forest Ranger Region 5 SAR reports from January 1, 2008, through December 31, 2009. The Forest Rangers of the Department of Environmental Conservation (DEC) Region 5 cover more than three quarters of the Adirondack Park. ${ }^{1}$ That area includes more than 2 million acres of forest preserve land, nearly half a million acres of conservation easement lands, 62,700 acres of state forests lands, 6900 acres of wildlife management lands, more than 3400 lakes and ponds ranging in size from high altitude ponds of an acre or less to water bodies the size of Lake Champlain, and 856 miles of wild, scenic, and recreational rivers. The Region 5 area also includes the High Peaks Wilderness Area. All reports were obtained from the New York State DEC. Data from the SAR reports were extracted and compiled into a structured database. Detailed information including number of persons, age, sex, activity, situation, cause of situation, ranger responses to SAR, SAR techniques, environmental factors, injuries, illnesses, reasons for situation, and victim's condition, experience, and equipment was recorded. Microsoft Excel (Microsoft Corp, Redmond, WA) was used for compiling data. The data were then exported to STATA (StataCorp, College Station, TX) for analysis using frequency counts. The Metrohealth Medical Center Institutional Review Board approved this study.

\section{Results}

From January 1, 2008, through December 31, 2009, New York State DEC Region 5 conducted 239 SAR missions involving at least 349 victims.

\section{DEMOGRAPHICS AND CONDITIONS}

Table 1 shows the demographics and activities of SAR victims. The majority of incidents involved hikers. Walkaway was not clearly defined nor consistently used in the SAR reports. Of the 7 walkaways, 4 were at the extremes of ages $(89,88,9$, and 2 years old) and had unintentionally walked away from a given location. The other 3 walkaways were a suicide, a runaway, and 1 found dead. The average age of the victims was 36 years. Cold exposure was the most common environmental condition associated with SAR $(72 ; 30 \%)$. The mean temperature was $13^{\circ} \mathrm{C}$. The range of temperatures was $-18^{\circ} \mathrm{C}$ to $35^{\circ} \mathrm{C}$. The mean elevation at which SAR occurred was $583 \mathrm{~m}$. The range of elevations was $76 \mathrm{~m}$ to $1596 \mathrm{~m}$.

\section{TYPES OF INCIDENTS}

Fifty-three percent (126) of the SAR missions were exclusively search; and 38\% (91) of SAR missions were exclusively rescue. Additionally, there were $16(7 \%)$ attempts to locate, $2(1 \%)$ recoveries, $3(1 \%)$ search and

Table 1. Demographics and activities of search and rescue victims

\begin{tabular}{lrr}
\hline Demographics & $n$ & $\%$ \\
\hline Sex & & \\
Female & 108 & 33.33 \\
Male & 216 & 66.67 \\
Age, years & & \\
$<18$ & 57 & 17.98 \\
$18-25$ & 74 & 23.34 \\
$26-44$ & 76 & 23.97 \\
$45-65$ & 80 & 25.24 \\
65+ & 30 & 9.46 \\
Activity & & \\
Hiking & 142 & 59.41 \\
Hunting & 16 & 6.69 \\
Camping & 15 & 6.28 \\
Other & 13 & 5.44 \\
Fishing & 9 & 3.77 \\
Snowmobiling & 7 & 2.93 \\
Walkaway & 7 & 2.93 \\
Walking & 7 & 2.93 \\
Skiing & 5 & 2.09 \\
Boating & 4 & 1.67 \\
Climbing & 3.26 \\
White water & 3 & 1.26 \\
Biking & 3 & 0.84 \\
Runaway & 2 & 0.84 \\
Suicide & 2 & 0.84 \\
Aircraft & 2 & 0.42 \\
Vehicle & 1 & 0.42 \\
\hline & 1 &
\end{tabular}




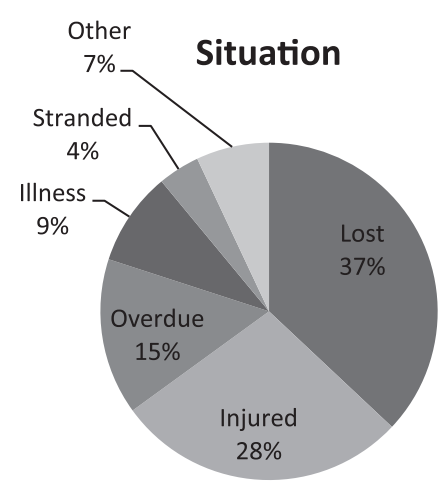

Figure 1. Situations creating need for search and rescue mission.

rescues, and $1(0.4 \%)$ rescue and recovery. Figure 1 shows the type of situation that caused the need for each SAR mission. Victims were either injured or ill in $65 \%$ of SAR missions. The cause of the situation was thought to be secondary to the victim in the majority of cases $(132 ; 56 \%)$ as determined by the forest ranger involved. Accidents $(46 ; 19 \%)$ were the second most common cause of an incident, followed by darkness $(28 ; 12 \%)$.

\section{REASONS FOR ILLNESS AND INJURIES}

Falling or slipping was the most frequent cause of injury, occurring in 49 cases (42\%) (Figure 2). Figure 3 shows the number of persons per age group whose incident was thought to be due to the victim exceeding his or her ability; the greatest number of these victims were 45 to 65 years old. Figure 4 shows the number of persons per age group who slipped or fell.

\section{MEDICAL CARE, ILLNESSES, AND INJURIES}

Medical care was required for the victim in 97 SAR missions $(46 \%)$. Persons aged 45 to 65 years accounted for more than one third of these cases, whereas persons less than 18 years old only accounted for 14 such cases (13\%). Of the victims aged 65 years or more, $33 \%$ required at least

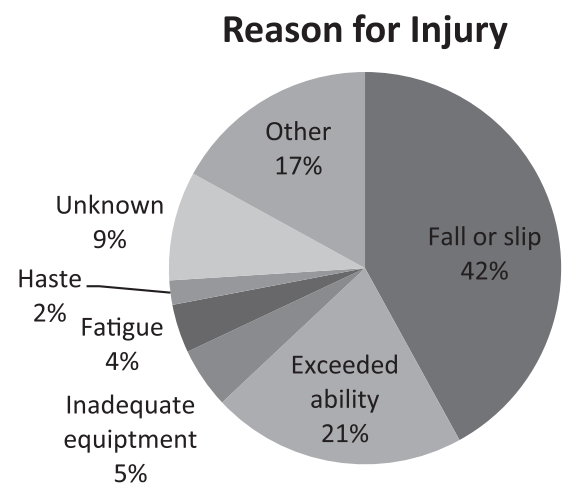

Figure 2. Cause of injury.

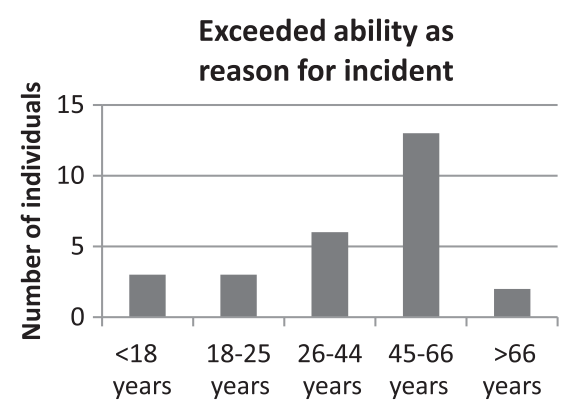

Figure 3. Exceeded ability as cause of incident, by age group.

emergency department medical care-that represents $11 \%$ of all victims requiring emergency department or greater level of care. More than half of the incidents resulted in some degree of injury $(111 ; 52 \%)$. Table 2 shows the breakdown in level of care needed for victims who sustained injury.

Other active conditions that were listed included general illnesses $(27 ; 22 \%)$, which included problems such as abdominal pain, vomiting, diarrhea, rashes and dental infections, problems with breathing $(8 ; 7 \%)$, heart attack or chest pain $(5 ; 4 \%)$, heat exposure $(5 ; 4 \%)$, shock $(3 ; 3 \%)$, drugs $(1 ; 1 \%)$, and other illnesses that did not fit into these categories $(36 ; 30 \%)$.

Soft tissue and skeletal systems were the most commonly reported traumatic injuries, 98 (49\%) and $56(28 \%)$, respectively. Traumatic injuries to internal organs $(15 ; 8 \%)$, circulatory system $(10 ; 5 \%)$, respiratory system $(4 ; 2 \%)$, nervous system $(2 ; 1 \%)$, and burns $(1 ; 1 \%)$ were also reported.

Over the 2-year period, there were 8 reported fatalities: 2 suicides, 1 snowmobiling accident, a private plane crash involving 2 victims, 1 fishing accident, 1 fall, and 1 victim who was found beneath the snow without clear cause of death.

\section{PRIOR PHYSICAL AND MEDICAL CONDITION}

Overall, the large majority of persons $(156 ; 90 \%)$ who required search efforts were in good physical condition.

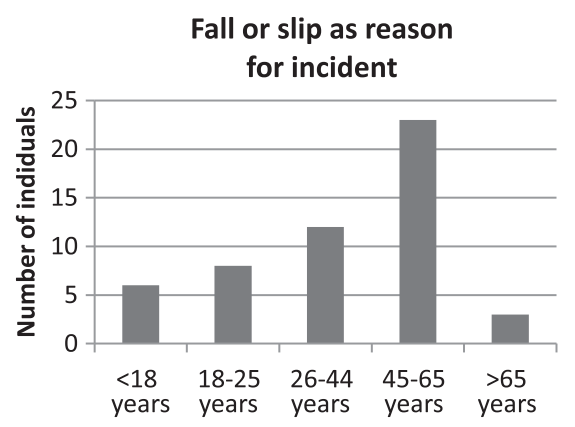

Figure 4. Fall or slip as cause of incident, by age group. 
Table 2. Extent of injury

\begin{tabular}{lrr}
\hline Extent of injury & $n$ & $\%$ \\
\hline None & 103 & 48.36 \\
Slight (required first aid) & 18 & 8.45 \\
Moderate (required treatment in ED) & 67 & 31.46 \\
Severe (required hospitalization) & 17 & 7.98 \\
Fatal & 8 & 3.76 \\
\hline
\end{tabular}

ED, emergency department.

In only $4(2.5 \%)$ documented search efforts were they deemed to be in poor physical condition. Of search victims, $42(17 \%)$ had some degree of known medical condition; 28 victims (10\%) were medication dependent, $9(4 \%)$ had illness or medical condition, and $5(3 \%)$ had Alzheimer's disease. More than half of victims (20; $56 \%$ ) who were either medication dependent or had a known illness or medical condition were more than 65 years old, and nearly one quarter $(8 ; 22 \%)$ were between 26 and 44 years old. Victims who were least likely to be medication dependent or have a known illness or medical condition were less than 26 years old (Figure 5).

\section{PREPARATION}

The majority of search mission victims $(93 ; 54 \%)$ had little experience with the activity in which they were involved; $9 \%$ had no experience with the activity (Table 3). Overall, 192 victims (66\%) had inadequate equipment and $139(45 \%)$ had inadequate clothing. Of 144 strictly search missions, only 62 of the parties (43\%) had any form of orientation equipment: $53 \%$ had a cell phone, $2(32 \%)$ had maps, and 23 (39\%) had compasses; 16 (11\%) had both map and compass with them, and $5(3.5 \%)$ had a GPS device with them.

\section{Discussion}

This study represents the first detailed review of Adirondack Park SAR reports. Victims were most frequently hiking, followed by hunting and camping, respectively. The majority of incidents were search missions for lost

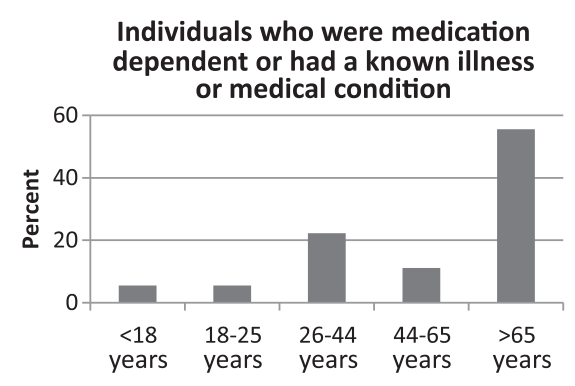

Figure 5. Victims who were medication dependent or had a known illness or medical condition, by age group.
Table 3. Victim experience in activity

\begin{tabular}{lcr}
\hline Experience & $n$ & $\%$ \\
\hline Much & 41 & 23.70 \\
Little & 93 & 53.76 \\
None & 15 & 8.67 \\
Unknown & 24 & 13.87 \\
\hline
\end{tabular}

persons. The second most common incident involved injured persons. More than half of the incidents were thought to be caused by factors involving the victim. The data suggest that the cause of many of the incidents was secondary to inadequate preparation by victims. Educating people who embark on activities within the Adirondack Park regarding appropriate preparation and planning is necessary to help reduce injuries and illness in the wilderness.

The age group 45 to 65 years old had the most frequent victims involved in SAR missions. This age group also had the highest percentage of victims whose incident resulted from exceeding their ability, who had a fall or slip causing an incident, and who required medical care. This age group may be most vulnerable, given the increasing number of older persons participating in outdoor activities despite limitations of physical and medical conditions.

Nearly half of SAR victims required some medical care, with nearly a third of them requiring at least emergency department care. Cold exposure was one of the most frequent environmental factors associated with illnesses recorded, and soft tissue injuries were the most frequent trauma recorded. That would be expected, given that the mean temperature was $13^{\circ} \mathrm{C}$ and wind was present in 179 incidents (75\%), conditions at which hypothermia can easily develop. Furthermore, it was recorded that 139 victims (45\%) did not have adequate clothing, making them even more vulnerable to the effects of cold exposure.

More than half of the victims had a known prior illness or medical condition or were medication dependent. The majority of these persons were aged more than 65 years. Although correlating a previous medical condition with need for SAR was not possible with our available data, this finding does highlight that persons with medical conditions and those who are medication dependent are using the Adirondack Park for recreational activities and may be vulnerable to injury and illness. First responders must be cognizant that SAR missions may be complicated by medical conditions that may predispose a victim to hypoglycemia, uncontrolled hypertension, or respiratory distress. 


\section{STUDY LIMITATIONS}

A limitation of this study is the variation in recording and documentation by forest rangers. For example, the reason for injury — such as haste, exceeded ability, and fatiguemay have been interpreted differently by different rangers. Another limitation of the study is that the extent of injury may be underestimated. If a victim initially declined transport to the hospital but later went by private vehicle, that would not be included in the report as requiring advanced medical care. Demographic data were only listed consistently for 3 victims in a party. There were 11 SAR reports of the 239 that involved more than 3 victims. These victims were not captured in the reports for various data points.

\section{Conclusion}

Our data suggest that safety efforts and SAR training should focus on educating the users of Adirondack Park about proper preparation and planning. Information tailored to injury prone groups, such as persons between 45 and 65 years old and persons with medical conditions, may be useful. The SAR forms should be expanded to allow for more detailed reporting on victims' health and medical preparedness. Listing vital signs, medical history, allergies, current required medication, medications being carried, how many days supply of medications carried, and assessment of first aid kits can assist in accomplishing this. Further, portraying the demographics of individual victims involved in SAR efforts may allow organizations providing SAR services to tailor their skills to specific demographic groups as well as to specific environmental conditions.

\section{Acknowledgments}

The authors would like to thank Captain John Strieff of the New York State Department of Environmental Conservation for his aid and support in this study.

\section{References}

1. Adirondack Forest Preserve. New York State Department of Environmental Conservation. Available at: http://www.dec.ny.gov/lands/5263.html. Accessed March 20, 2013.

2. Heggie TW. Search and rescue in Alaska's national park. Travel Med Infect Dis. 2008;6:355-361.

3. Boore SM, Bock D. Ten years of search and rescue in Yosemite National Park: examining the past for future prevention. Wilderness Environ Med. 2013;24:2-7.

4. Heggie TW, Amundson ED. Dead man walking: search and rescue in US national parks. Wilderness Environ Med. 2009:20:244-249.

5. Heggie TW, Heggie TM. Search and rescue trends and the emergency medical service workload in Utah's national parks. Wilderness Environ Med. 2008;19: 164-171.

6. Adams AL, Schmidt TA, Newgard CD, et al. Search is a time-critical event: when search and rescue missions may become futile. Wilderness Environ Med. 2007;18: 95-101.

7. Ela GK. Epidemiology of wilderness search and rescue in New Hampshire, 1999-2001. Wilderness Environ Med. 2004;15:11-17.

8. Wild FJ. Epidemiology of mountain search and rescue operations in Banff, Yoho, and Kootenay National Parks, 2003-06. Wilderness Environ Med. 2008;19: 245-251.

9. McIntosh SE, Brillhard A, Dow J, Grissom CK. Search and rescue activity on Denali, 1990 to 2008. Wilderness Environ Med. 2010;21:103-108.

10. Hung EK, Townes DA. Search and rescue in Yosemite National Park: a 10-year review. Wilderness Environ Med. 2007;18:111-116.

11. Cordell HK. The latest on trends in outdoor nature-based recreation. Forest Hist Today. Spring 2008.

12. Emerging markets for outdoor recreation in the United States. USDA Forest Service, April 1997. Available at: http://www.srs.fs.usda.gov/trends/research/emerging-mar kets.html. 